\title{
The Structure of OECD Unemployment
}

\author{
Taylor Collins \\ University of the Incarnate Word
}

In this paper, I apply a set of unit root tests on 31 OECD countries in order to uncover evidence on the best way to model their unemployment rates. There are three primary classes of theories into how the unemployment rate evolves (natural rate theories, hysteresis theories, and structural theories) and they each have very distinct statistical properties related to unemployment persistence. In this paper, I use a set of Markov-Switching Augmented Dickey Fuller tests to find evidence that 20 of the 31 countries could be better modeled by structuralist theories of unemployment than by hysteresis theories or natural rate of unemployment theories. These results provide comparable evidence supporting structural theories of unemployment to previous papers that have used different sets of unit root testing techniques.

Keywords: unemployment, hysteresis, natural rate, structural, Markov-Switching

\section{INTRODUCTION}

The purpose of this paper is to test for the presence of unit roots in the unemployment rates of 31 OECD countries. Unit root testing of unemployment series has been a common endeavor ever since Blanchard and Summers' (1986) Hysteresis paper cast doubts on the longstanding dominance of the natural rate theories of Phelps (1967, 1968) and Friedman (1968), particularly amongst the unemployment rates of European countries. This paper will follow in the line of Papell, Murray, and Ghiblawi (2000) (hereafter referred to as PMG) in that I will utilize unit root testing in an attempt to find evidence supporting one of three general sets of unemployment theories: traditional natural rate theories, hysteresis theories, or structural theories. Even with an extra 20 years' worth of data, an expanded range of countries, and alternate unit root testing techniques, I find a comparable level of evidence supporting structural theories of unemployment as PMG.

The traditional theories of Phelps and Friedman describe the unemployment rate as fluctuating in the short term, but always gravitating back to a "natural rate" of unemployment, generally defined as some market equilibrium. Since the unemployment rate is always gravitating back to some natural level, all shocks to the economy only have a temporary effect on unemployment. Thus, these theories imply that the unemployment rate should be stationary.

Blanchard and Summers concluded that these theories failed to well-describe what was happening to European unemployment rates. As a result, they proposed an alternative theory for unemployment, one they termed hysteresis. As defined by Blanchard and Summers, hysteresis is "a very high dependence of current unemployment on past unemployment." Rather than shocks only having temporary effects, hysteresis posits that temporary shocks will permanently alter the level of unemployment. Empirically, this should mean that the unemployment series is non-stationary. 
Finally, structuralist theories of unemployment are characterized by "endogenizing the natural rate of unemployment - defined now as the current equilibrium steady state rate, given the current capital stock and any other state variables," as defined by Phelps (1994). As with the traditional theories of unemployment, structuralist theories maintain that the equilibrium path of unemployment is approaching a natural rate. However, in the structuralist theories of unemployment, the natural rate can move over time. According to the structuralist theories, most shocks to unemployment will only cause temporary movements around the natural rate, but there are some which will cause a permanent change in the unemployment rate itself. Empirically, structuralist theories expect to see the unemployment rate be stationary around a process that is subject to a few structural breaks.

This sets up a natural test to perform. If statistical evidence of a unit root is found in an unemployment series, this can be taken as evidence that a hysteresis model might most appropriately describe the behavior of that unemployment series. If evidence of stationarity is found, this would lead researchers to choose models more consistent with natural rate theories. And if stationarity around a process with structural breaks is found, it will point towards structuralist models being most appropriate. This paper is meant to contribute to the field of unit root testing unemployment rates by applying different unit root testing techniques to an expanded sample of 31 OECD countries using modern data. I conduct a total of 3 separate unit root tests for each of the 31 countries in my sample.

The analysis of the results of these tests can occur across two different spectrums. First, if any given test yields the same conclusion across an overwhelming majority of countries, it can be taken as evidence that the theory associated with that particular outcome is likely the appropriate unemployment model to use when choosing an arbitrary country. Second, if any given country yields the same conclusion across the spectrum of unit root tests conducted, this can be taken as particularly strong evidence that the given country should be modeled according to the corresponding model.

To conduct this analysis, I use a total of 3 unit root tests in all. I begin with the commonly used Augmented Dickey Fuller test and Dickey Fuller Generalized Least Squares test as a starting point. These tests are widely known and understood, and so they serve as a good baseline for the paper. In addition, they are tools that have been around for a long time, so they are prevalent in much of the research from the 1990s that originally explored the questions of hysteresis vs natural rate of unemployment queries. So, reapplying them to modern datasets can be highly illuminating.

Then, in order to test for the potential validity of structural theories of unemployment, I next conduct a Markov Switching unit root test. None of the lags in this regression are regime dependent, only the intercept. This allows me to conduct a unit root test on the series while also allowing two distinct "natural rates" to which the unemployment rate might gravitate towards over time. One of the advantages of this framework is the highly flexible nature of the test, as it may find evidence of only a single regime switch over time in which the economy shocks from one natural rate of unemployment to another, or it may well describe an economy which is continuously switching between two distinct unemployment regimes, each with its own natural rate of unemployment. In the last decade, researchers have started using this test to look for regimeswitching stationarity in unemployment rates, but these studies have all been focused on a small number of countries (Oliskevych and Lukianenko (2020)), or even just a single one (Bayat et. al (2020), Cevik and Dibooglu (2013)). To my knowledge, no paper has yet applied the Markov Switching Augmented Dickey Fuller test to the unemployment rates of a large number of countries, as I do in this paper.

For each of these tests, I use quarterly unemployment rates pulled from the OECD (2020) statistics portal. All series end on 2019Q4 to prevent any unemployment rate outliers associated with the pandemic from skewing the results. The date of each country's series begins based on data availability, with the longest series starting in 1955Q1 and the shortest starting in 1998Q2.

The rest of the paper proceeds as follows. Section 2 establishes a baseline of understanding for the paper by conducting the well-established ADF and DF-GLS tests. Section 3 incorporates non-linearity using a Markov Switching Augmented Dicky Fuller test. And section 4 concludes. 


\section{LINEAR UNIT ROOT TESTS}

I want to begin this study by testing for unit roots using some of the oldest and most widely known unit root tests available. In this section, two tests will be conducted in order to establish a baseline around which we can compare results using recent unemployment data to past unit root testing research. The two tests I utilize in this section will be the Augmented Dickey Fuller test (ADF) and the Dickey Fuller Generalized Least Squares test (DF-GLS). I run these tests on each of the 31 individual OECD countries.

Neither of these tests allow the presence of structural change, so they are ill-equipped to evaluate the appropriateness of structural theories of unemployment. Rather, these tests will be useful in evaluating Hysteresis theories against Natural Rate of Unemployment theories directly, as Blanchard and Summers first explored. The purpose of this section will be to see whether or not updated data would lead researchers to different conclusions from those in the early 90's that found that natural rate of unemployment theories were ill-equipped to describe the dynamics of European unemployment rates. This section establishes a baseline of understanding by using long established tests that would have been used by researchers in the 90's. The following section then updates this query to utilize a Markov-Switching model that allows the presence of structural dynamics.

\section{Augmented Dickey Fuller Test}

The ADF test I utilize is conducted by first estimating the following regression:

$\Delta u_{t}=c+\alpha u_{t-1}+\sum_{k=1}^{n} \rho_{k} \Delta u_{t-k}+\varepsilon_{t}$

where $u_{t}$ is the unemployment rate. The variable of interest in this regression is $\alpha$. If $\alpha=0$, this regression will be indicative of a unit root containing process. If $\alpha<0$, the regression reduces to a stationary process. This allows the construction of a simple 1-sided hypothesis test:

$H_{0}$ - Unemployment is nonstationary: $\alpha<0$

$H_{1}$ - Unemployment is stationary: $\alpha=0$

For my choice of the number of first difference lags to include, I use the General to Specific selection method utilized by Campbell and Perron (1991), Hall (1994), and $\mathrm{Ng}$ and Perron (1995). Starting with a maximum possible value for $n$ as $n_{\max }=12$, I check the test statistic of the coefficient of the last lag for significance. If the last lag is significant, I set $n=12$. If not, I lower $n$ by 1 and repeat the significance test on the new last lag. This process is repeated until the last lag is significant.

The key results of the ADF test are reported in Table 1. Using critical values of MacKinnon (1996), I find that the unit root null can be rejected at the $10 \%$ significance level for only 9 of the 31 countries observed. In addition, Table 1 reports the half-lives for an unemployment shock in each of the 31 estimated regressions, defined as $H L_{i}=\frac{\ln (0.5)}{4 \ln \left(1+\alpha_{i}\right)}$ where $i$ denotes a country. This measure is reported in years and is of value in helping us determine the degree of persistence of a shock to each individual country. The longer the half-life, the greater the support for Hysteresis theories; the shorter the half-life, the greater the support for natural rate of unemployment theories. The half-lives vary from less than two years (South Korea, Chile, Mexico, Estonia) to over 86 years (Luxembourg). In total, the unit root null can be rejected for only 9 of the 31 countries observed, providing very little evidence for natural rate of unemployment theories over hysteresis theories in these countries. This conclusion falls in line with that of Blanchard and Summers, which finds little evidence of a natural rate of unemployment, particularly within Western European nations. 
TABLE 1

ADF TEST RESULTS

\begin{tabular}{|c|c|c|c|c|c|c|c|}
\hline Country & $\alpha$ & Lags & HL & Country & $\alpha$ & Lags & HL \\
\hline Australia & -0.020 & 9 & 8.58 & Latvia & -0.064 & 12 & 2.62 \\
\hline Austria & -0.025 & 8 & 6.84 & Lithuania & $-0.056^{*}$ & 6 & 3.01 \\
\hline Belgium & -0.058 & 8 & 2.90 & Luxembourg & 0.002 & 12 & 86.56 \\
\hline Canada & -0.017 & 12 & 10.11 & Mexico & $-0.091^{* *}$ & 10 & 1.82 \\
\hline Chile & $-0.096^{* *}$ & 7 & 1.72 & The Netherlands & -0.018 & 10 & 9.54 \\
\hline Czech Republic & -0.019 & 1 & 9.03 & New Zealand & -0.042 & 9 & 4.04 \\
\hline Denmark & $-0.045^{* *}$ & 6 & 3.76 & Norway & -0.025 & 1 & 6.844 \\
\hline Estonia & -0.085 & 11 & 1.95 & Poland & -0.009 & 11 & 19.17 \\
\hline Finland & $-0.040^{* *}$ & 7 & 4.24 & Portugal & -0.021 & 9 & 8.16 \\
\hline France & -0.026 & 11 & 6.58 & Slovakia & -0.017 & 6 & 10.11 \\
\hline Germany & -0.006 & 12 & 28.79 & Slovenia & -0.074 & 12 & 2.25 \\
\hline Hungary & $-0.046^{*}$ & 9 & 3.68 & Spain & $-0.017 *$ & 3 & 10.11 \\
\hline Ireland & -0.015 & 11 & 11.47 & Sweden & -0.025 & 10 & 6.84 \\
\hline Israel & -0.006 & 5 & 28.79 & United Kingdom & -0.014 & 12 & 12.29 \\
\hline Japan & -0.009 & 11 & 19.17 & United States & $-0.039^{* *}$ & 12 & 4.36 \\
\hline South Korea & $-0.102^{* *}$ & 4 & 1.61 & & & & \\
\hline
\end{tabular}

\section{Dickey Fuller Generalized Least Squares Test}

The second linear unit root test I conduct is the DF-GLS test first proposed by Elliot, Rothenberg, and Stock (1996). This test is similar to the ADF test, with the key difference being that the DF-GLS test requires first demeaning the time series via Generalized Least Squares before running the ADF regression. This test is appealing because it is known to have substantially improved power over the ADF test when an unknown mean or trend is present.

The test proceeds as follows. First, let $z_{t}=1$ and define $T$ as the number of observations in a given country's unemployment rate time series. Then, demean the time series by regressing $\left[u_{1},(1-\right.$ $\left.a L) u_{2}, \ldots,(1-a L) u_{T}\right]$ on $\left[z_{1},(1-a L) z_{2}, \ldots,(1-a L) z_{T}\right]$ to yield a $\hat{\beta}_{G L S}$. In this regression, $a=1+\frac{\bar{c}}{T}$ and $\bar{c}=-7$. The demeaned unemployment rate is then calculated as $u_{t}^{r}=u_{t}-z_{t} \hat{\beta}_{G L S}$. This demeaned unemployment rate is then used to estimate an ADF regression.

$\Delta u_{t}^{r}=\alpha u_{t-1}^{r}+\sum_{k=1}^{n} \rho_{k} \Delta u_{t-k}^{r}+\varepsilon_{t}$

This regression has the same variable of interest, $\alpha$, as the ADF test. The hypothesis test of value is the same as the ADF test:

$H_{0}$ - Unemployment is nonstationary: $\alpha<0$

$H_{1}$ - Unemployment is stationary: $\alpha=0$

For the choice of the number of lags included, I use the Modified Akaike Information Criteria, with the maximum number of lags allowed again set to 12. Critical values come from MacKinnon (1996). Key results of the DF-GLS test are reported in Table 2. Using this test, the unit root null can only be rejected at the $10 \%$ significance level for 13 of the 31 countries considered. Half-lives are again calculated and are generally much higher than those found by the ADF test. So while this test does generate more unit root null rejections, the better statistical properties of this test also highlight much more persistence in the shocks to the unemployment series of these 31 countries than does the first, providing further evidence for the use of hysteresis models over natural rate of unemployment models. This is particularly true for the Western European countries at the center of the Blanchard and Summers research, as I fail to reject non-stationarity 
in the unemployment rates of Austria, Belgium, The Czech Republic, Denmark, France, Germany, Luxembourg, The Netherlands, Norway, and The United Kingdom.

TABLE 2

DF-GLS TEST RESULTS

\begin{tabular}{|c|c|c|c|c|c|c|c|}
\hline Country & $\alpha$ & Lags & HL & Country & $\alpha$ & Lags & HL \\
\hline Australia & -0.005 & 2 & 34.57 & Latvia & $-0.046^{*}$ & 4 & 3.68 \\
\hline Austria & -0.009 & 4 & 19.17 & Lithuania & $-0.035^{* *}$ & 4 & 4.86 \\
\hline Belgium & -0.005 & 8 & 34.57 & Luxembourg & -0.005 & 4 & 34.57 \\
\hline Canada & -0.007 & 12 & 24.67 & Mexico & $-0.051^{* *}$ & 1 & 3.31 \\
\hline Chile & -0.005 & 1 & 34.57 & The Netherlands & -0.003 & 1 & 57.68 \\
\hline Czech Republic & -0.015 & 1 & 11.47 & New Zealand & $-0.020^{*}$ & 4 & 4.04 \\
\hline Denmark & -0.013 & 4 & 13.24 & Norway & -0.019 & 1 & 9.03 \\
\hline Estonia & $-0.060^{* *}$ & 4 & 2.66 & Poland & -0.010 & 2 & 17.24 \\
\hline Finland & $-0.014^{* *}$ & 2 & 12.29 & Portugal & $-0.016^{* *}$ & 2 & 10.74 \\
\hline France & -0.010 & 4 & 17.24 & Slovakia & -0.010 & 4 & 17.24 \\
\hline Germany & -0.001 & 12 & 173.20 & Slovenia & $-0.046^{*}$ & 3 & 3.70 \\
\hline Hungary & -0.007 & 2 & 24.67 & Spain & $-0.010^{*}$ & 1 & 17.24 \\
\hline Ireland & $-0.011^{*}$ & 11 & 15.67 & Sweden & $-0.011^{*}$ & 3 & 15.67 \\
\hline Israel & -0.006 & 4 & 43.23 & United Kingdom & -0.002 & 1 & 86.56 \\
\hline Japan & -0.008 & 12 & 21.57 & United States & $-0.021^{* *}$ & 12 & 8.16 \\
\hline South Korea & $-0.054^{* *}$ & 3 & 3.12 & & & & \\
\hline
\end{tabular}

Though this is noteworthy, it is not entirely surprising; the ADF test and DF-GLS test have both been used to test for a unit root in unemployment series often and many papers have found that they tend to fail to reject the unit root null, particularly in Western European nations. But these two tests do establish a baseline. The key question of the next section is whether or not a modern test with switching behavior leads to the same conclusion.

\section{NONLINEAR UNIT ROOT: MARKOV SWITCHING AUGMENTED DICKEY FULLER TEST}

In this section, I employ a version of a Markov Switching Augmented Dickey Fuller (MS-ADF) test for each country. This test will be run specifically so that two distinct states-of-the-world exist for each country; one with a high-unemployment long run equilibrium level of unemployment and the other with a low-unemployment long run equilibrium level of unemployment. The transition between the two states of the world are dictated by a first-order Markov process so as to probabilistically determine which of the two states of the world are most likely. This allows the number of permanent shocks to the unemployment rate to be relatively high as we could see significant switching between states of the world, while also allowing the possibility of there being only a single switch, or even no switches at all. But the types of switching is still constrained to be small, so that the world is always described by one of only two distinct states. This dynamic could well describe markets which, for example, fluctuate between periods of recessions and expansions, each of which are characterized by distinct long run equilibrium levels of unemployment if we were to remain in that state in perpetuity.

The regime switching unit root test was first proposed by Hall, Psaradakis, and Sola (1999) to test for periodically collapsing bubbles and has since been used in a wide range of papers (Holmes (2008); Chen (2008); Camacho (2011); Cevik and Digbooglu (2013) for example). The MS-ADF test takes the same basic functional form as the linear ADF test, but it incorporates the existence of multiple regimes, or states of the world, in order to capture dynamics that potentially change across time.

The MS-ADF test I use takes the form 
$\Delta u_{t}=c_{s_{t}}+\alpha u_{t-1}+\sum_{k=1}^{n} \rho_{k} \Delta u_{t-k}+\varepsilon_{t} \quad \varepsilon_{t} \sim N I D(0, \Sigma)$

where $u_{t}$ is the unemployment rate, $s_{t} \in\{1,2\}$ is the unobservable regime, $c_{s_{t}}, \alpha$, and $\rho_{k}$ are parameters to be estimated, and $\Sigma$ is the error variance.

I assume that the state variable follows a two regime Markov process. In accordance with Hamilton (1994), a first order Markov switching process dictates the evolution of the unobserved state variable.

$$
\begin{aligned}
& P\left[s_{t}=1 \mid s_{t-1}=1\right]=p \\
& P\left[s_{t}=2 \mid s_{t-1}=1\right]=1-p \\
& P\left[s_{t}=2 \mid s_{t-1}=2\right]=q \\
& P\left[s_{t}=1 \mid s_{t-1}=2\right]=1-q \\
& 0<p<1 \quad 0<q<1
\end{aligned}
$$

As with the linear ADF test, the key variable of interest in determining stationarity of the series is $\alpha$. Stationarity can be tested with the following one-sided hypothesis test:

$H_{0}$ - Unemployment is nonstationary: $\alpha<0$

$H_{1}$ - Unemployment is stationary: $\alpha=0$

The regime probabilities are estimated using maximum likelihood estimation based on the expectations maximization algorithm of Hamilton (1994) and Krolzig (1997). The number of first difference lags $(n)$ was chosen to be equal to the linear ADF test so that I may run a Likelihood Ratio test on the fit of the linear regression compared to the regime switching one. The goal of this test is to determine whether or not the regime switching test provides a statistically significantly improved fit over the linear unit root test. In this test, the null hypothesis is that the linear model provides as good a fit as the non-linear one, so rejection of the null indicates a statistically significantly superior fit for the regime-switching regression. Of the 31 countries considered, 8 countries failed to reject the null of the Likelihood Ratio test (Czech Republic, Estonia, France, Hungary, Luxembourg, New Zealand, Norway, and Slovenia). Of these eight, Estonia, Hungary, New Zealand, and Slovenia all rejected the unit root null in either the ADF or the DF-GLS test. These results lend evidence to the assertions that unemployment in Estonia, Hungary, New Zealand, and Slovenia could be modeled using Natural rate of unemployment models over structural theories. On the other hand, The Czech Republic, France, Luxembourg, and Norway did not reject the unit root null in any of the tests, meaning I have uncovered no evidence that either natural rate of unemployment models or structural models would be appropriate for any of their unemployment rates. Instead, researchers should consider hysteresis models for these four countries.

For the remaining 23 countries, Table 3 reports the coefficient of the first lag of the level of unemployment $(\alpha)$, the estimated probabilities of remaining in each regime in period $t$ when already in that regime in period $t-1$ ( $p$ for regime $1, q$ for regime 2 ), the estimated intercept for each regime $\left(c_{i}\right)$, and the calculated half-life of a shock to each country's unemployment rate. As with previous tests, finding $\alpha$ significantly less than 0 indicates rejection of the null of persistence of shocks to unemployment in favor of stationarity.

TABLE 3

MS-ADF TEST RESULTS

\begin{tabular}{|c|c|c|c|c|c|c|}
\hline Country & $\mathrm{c}_{\mathrm{L}}$ & $\mathrm{c}_{\mathrm{H}}$ & $\alpha$ & $\mathrm{p}$ & $\mathrm{q}$ & $\mathrm{HL}$ \\
\hline Australia & 0.144 & 0.795 & $\begin{array}{c}-0.032^{* * *} \\
(0.007)\end{array}$ & 0.965 & 0.706 & 5.29 \\
\hline Austria & 0.099 & 0.648 & $\begin{array}{c}-0.034^{* *} \\
(0.013)\end{array}$ & 0.936 & 0.298 & 4.99 \\
\hline Belgium & 0.175 & 1.064 & $\begin{array}{c}-0.029 \\
(0.024)\end{array}$ & 0.951 & 0.000 & 5.89 \\
\hline Canada & 0.132 & 0.905 & $\begin{array}{c}-0.023^{* * *} \\
(0.009)\end{array}$ & 0.975 & 0.507 & 7.32 \\
\hline
\end{tabular}




\begin{tabular}{|c|c|c|c|c|c|c|}
\hline Chile & 0.617 & 1.789 & $\begin{array}{c}-0.092 * * * \\
(0.030)\end{array}$ & 0.966 & 0.559 & 1.79 \\
\hline Denmark & 0.006 & 0.428 & $\begin{array}{c}-0.050 * * * \\
(0.012)\end{array}$ & 0.000 & 0.812 & 3.37 \\
\hline Finland & 0.437 & 1.340 & $\begin{array}{c}-0.058^{* * * *} \\
(0.010)\end{array}$ & 0.961 & 0.754 & 2.91 \\
\hline Germany & 0.019 & 0.312 & $\begin{array}{c}-0.018 * * * \\
(0.004)\end{array}$ & 0.953 & 0.880 & 9.43 \\
\hline Ireland & 0.126 & 1.051 & $\begin{array}{c}-0.021 * * \\
(0.006)\end{array}$ & 0.976 & 0.642 & 8.20 \\
\hline Israel & 0.016 & 0.511 & $\begin{array}{c}-0.009^{* *} \\
(0.004)\end{array}$ & 0.938 & 0.495 & 19.60 \\
\hline Japan & 0.036 & 0.422 & $\begin{array}{c}-0.016^{* * * *} \\
(0.005)\end{array}$ & 0.988 & 0.412 & 10.88 \\
\hline South Korea & 0.339 & 2.306 & $\begin{array}{c}-0.104 * * * \\
(0.021)\end{array}$ & 0.991 & 0.496 & 1.57 \\
\hline Latvia & 0.439 & 2.910 & $\begin{array}{c}-0.064^{*} \\
(0.034)\end{array}$ & 0.971 & 0.663 & 2.61 \\
\hline Lithuania & 0.533 & 1.875 & $\begin{array}{c}-0.066^{* *} \\
(0.032)\end{array}$ & 0.944 & 0.542 & 2.52 \\
\hline Mexico & 0.324 & 1.430 & $\begin{array}{c}-0.088^{* * * *} \\
(0.027)\end{array}$ & 0.991 & 0.487 & 1.88 \\
\hline The Netherlands & 0.075 & 0.238 & $\begin{array}{c}-0.025 \\
(0.019) \\
\end{array}$ & 0.916 & 0.849 & 6.82 \\
\hline Poland & 0.018 & 0.629 & $\begin{array}{c}-0.034 * * * \\
(0.007)\end{array}$ & 0.884 & 0.823 & 4.98 \\
\hline Portugal & 0.290 & 0.699 & $\begin{array}{c}-0.042 * * * \\
(0.010)\end{array}$ & 0.990 & 0.929 & 4.08 \\
\hline Slovakia & 0.019 & 1.314 & $\begin{array}{c}-0.006 \\
(0.009)\end{array}$ & 0.979 & 0.324 & 31.42 \\
\hline Spain & 0.195 & 1.525 & $\begin{array}{c}-0.014 * * * \\
(0.006)\end{array}$ & 0.991 & 0.472 & 12.56 \\
\hline Sweden & 0.154 & 0.845 & $\begin{array}{c}-0.028 * * * \\
(0.008)\end{array}$ & 0.963 & 0.377 & 6.04 \\
\hline United Kingdom & 0.106 & 0.450 & $\begin{array}{c}-0.027 * * * \\
(0.009)\end{array}$ & 0.923 & 0.585 & 6.35 \\
\hline United States & 0.194 & 0.823 & $\begin{array}{c}-0.042 * * * \\
(0.010)\end{array}$ & 0.967 & 0.644 & 4.05 \\
\hline
\end{tabular}

Running this test, I now reject the null of a unit root in favor of stationarity with breaks for 20 of the 31 countries at the $10 \backslash \%$ significance level. This portion is closely in line with the findings of Papell, Murray and Ghiblawi, who rejected their unit root null in favor of stationarity with a break for 10 of 16 countries considered.

In the 20 countries in which I reject the unit root null, shocks to unemployment are estimated to dissipate over time and the process will revert to some "mean" level of unemployment. The only thing this test does differently than the original ADF test that I ran is that it allows the economy's mean unemployment rate to fluctuate between 2 different levels. Thus, for these 20 countries rejecting the unit root null, a structuralist theory of unemployment is likely to be the most fitting model. Further, we note that the half-lives of unemployment shocks have fallen substantially when incorporating non-linearity in the MS-ADF relative 
to the two linear tests, again lending more evidence to a structural theory of unemployment being appropriate.

\section{CONCLUSIONS}

This paper provides an updated answer to an old question: how should we model the evolution of the unemployment rate? While this question has been studied through the use of unit root testing by many in the past, I update that line of research by using modern techniques, newer data, and more countries.

Using a Markov Switching Augmented Dickey Fuller test, I uncover evidence that the majority of the OECD countries studied (20 out of 31 ) should be modeled using structural theories of unemployment over natural rate of unemployment theories or hysteresis theories. What's more, the half-life of the shocks to the unemployment rate fell significantly when allowing for this switching behavior, as opposed to the linear unit root tests I conducted as a baseline. In not allowing the dynamics of the world to change, linear unit root tests find a much larger persistence in unemployment shocks than what I found in the MS-ADF test.

Of the remaining 11 countries that are not well described by structural theories of unemployment, there is evidence to support using natural rate of unemployment theories for Estonia, Hungary, New Zealand, and Slovenia. On the other hand, there is no evidence to support either natural rate of unemployment or structural theories of unemployment for Belgium, The Czech Republic, France, Luxembourg, The Netherlands, Norway, or Slovakia. Perhaps not coincidentally, the majority of these are Western European countries, lending at least some credibility to the original findings of Blanchard and Summers. However, the presence of hysteresis certainly still seems far less prevalent than they these authors concluded in 1986, as many European nations also seem to be well described by structural theories of unemployment.

In aggregate, this paper uncovers statistical evidence supporting the assertion that structural theories of unemployment are most appropriate for the widest range of OECD countries, but that there are isolated instances in which traditional natural rate of unemployment theories should still be considered. In addition, since there appears to be a cluster of Western European countries for whom hysteresis models may still be appropriate, researchers should be extra careful when modeling unemployment in this region, as unemployment dynamics here appear less likely to converge to the those of the rest of the OECD. More research is needed to determine why these Western European nations possess unemployment dynamics inconsistent with the rest of the OECD world.

\section{REFERENCES}

Bayat, T., Kayhan, S., \& Kocyigit, A. (2013). Asymmetric Behavior of Unemployment Analysis with Regime Switching Models in Turkey. Business and Economics Research Journal, 4(2), 1-79.

Blanchard, O., \& Summers, L. (1986). Hysteresis and the European Unemployment Problem. In S. Fischer (Ed.), NBER Macroeconomics Annual (pp. 15-78).

Camacho, M. (2011). Markov-switching models and the unit root hypothesis in real US GDP. Economics Letters, 112, 161-164.

Campbell, J., \& Perron, P. (1991). Pitfalls and Opportunities: What Macroeconomists Should Know About Unit Roots. In O. Blanchard \& S. Fischer (Eds.), NBER Macroeconomic Annual (pp. 141201).

Cevik, E., \& Digbooglu, S. (2013). Persistence and non-linearity in US unemployment: A regimeswitching approach. Economic Systems, 37(1), 61-68.

Chen, S-W. (2008). Non-stationarity and non-linearity in the stock prices: Evidence from the OECD countries. Economics Bulletin, 3, 1-11.

Dickey, D.A., Fuller, W.A. (1979). Distribution of the estimators for autoregressive time series with a unit root. Journal of the American Statistical Association, 74, 427-431.

Elliott, G., Rothenberg, T.J., \& Stock, J.H. (1996). Efficient tests for an autoregressive unit root. Econometrica, 64, 813-836.

Friedman, M. (1968). The Role of Monetary Policy. American Economic Review, 58, 1-17. 
Hall, A. (1994). Testing for a Unit Root in Time Series with Pretest Data-Based Model Selection. Journal of Business and Economic Statistics, 12, 461-70.

Hall, S.G., Psaradakis, Z., \& Sola, M. (1999). Detecting periodically collapsing bubbles: A Markovswitching unit root test. Journal of Applied Econometrics, 14, 143-154.

Hamilton, J.D. (1994). Time Series Analysis. Princeton University Press, Princeton, NJ.

Holmes, M.J. (2008). Real exchange stationarity in Latin America and relative purchasing power parity: Regime switching approach. Open Economics Review, 19, 261-275.

Krolzig, H. (1997). Markov-Switching Vector Autoregressions Modeling, Statistical Inference and Application to Business Cycle Analysis. Springer, Berlin.

MacKinnon, J.G. (1996). Numerical Distribution Functions for Unit Root and Cointegration Tests. Journal of Applied Econometrics, 11(6), 601-18.

Ng, S., \& Perron, P. (1995). Unit Root Tests in ARMA Models with Data Dependent Methods for the Selection of the Truncation Lag. Journal of the American Statistical Association, 90, 268-281.

OECD. (2020). Short-Term Labour Market Statistics. ABS, INE, CBS, Statistics Bureau of Japan, Statistics Korea, INEGI, Statistics New Zealand, BLS. Retrieved December 13, 2020, from https://stats.oecd.org

Oliskevych, M., \& Lukianenko, I. (2020). European Unemployment Nonlinear Dynamics over the Business Cycles: Markov Switching Approach. Global Business and Economics Review, 22(4).

Papell, D., Murray C., \& Ghiblawi, H. (2000). The Structure of Unemployment. The Review of Economics and Statistics, 82(2), 309-315.

Phelps, E. (1968). Money Wage Dynamics and Labor Market Equilibrium. Journal of Political Economy, 76, 678-711.

Phelps, E. (1994). Structural Slumps: The Modern Equilibrium Theory of Unemployment, Interest, and Assets. Cambridge, MA: Harvard University Press. 